\title{
Pax6 is required for the normal development of the forebrain axonal
} \section{connections}

\author{
Lucy Jones ${ }^{1, *}$, Guillermina López-Bendito ${ }^{1, *}$, Peter Gruss², Anastassia Stoykova² and Zoltán Molnár ${ }^{1, \dagger}$ \\ 1 Department of Human Anatomy and Genetics, University of Oxford, South Parks Road, Oxford OX1 3QX, UK \\ 2Max-Planck Institute of Biophysical Chemistry, Department of Molecular Cell Biology, 37077 Gottingen, Germany \\ *These authors contributed equally to this work \\ †Author for correspondence (e-mail: zoltan.molnar@anat.ox.ac.uk) \\ Accepted 25 July 2002
}

\section{SUMMARY}

The transcription factor PAX6 has been implicated in forebrain patterning, cerebral cortical arealization and in development of thalamocortical connections. Using a Pax6/lacZ knockout mouse, in which the endogenous Pax6 expression is reflected by $\beta$-galactosidase activity, we have studied the consequences of the loss of Pax6 function on thalamocortical (TCA) and corticofugal axon (CFA) pathfinding during the period of embryonic day (E) 14.5 to E18.5. Carbocyanine dye tracing in Pax6 heterozygotes $\left(\right.$ Pax6 $\left.^{+/-}\right)$and Pax6 wild-type $\left(\right.$Pax6 $\left.^{+/+}\right)$brains revealed that CFAs and TCAs temporarily arrested their growth at E14.5 at the border of the $\beta$-galactosidase-positive region at the pallial/subpallial boundary (PSPB), before they continued towards their targets. However, in Pax6 homozygous $\left(\right.$ Pax6 $\left.^{--}\right)$embryos, CFAs and TCAs were unable to encounter each other at the PSPB and reach their final targets. Instead of crossing the PSPB, they had the tendency to descend into the ventral pallium in large aberrant fascicles. In addition, cells with a presumptive guide-post function, which are normally situated in the ventral thalamus, internal capsule and hypothalamus, were more dispersed in the hypothalamus and ventral pallium. These pathfinding defects were confirmed by immunohistochemistry for L1 and TAG1, markers of the early axonal connections. The aberrant development of axonal connections in absence of Pax6 function appear to be related to ultrastructural defects of cells along the PSPB, as well as to a failure of axonal guidance molecule expression, including Sema3c and Sema5a.

Key words: Axon guidance, Patterning, Telencephalon, Semaphorins, Mouse, Pallial/subpallial boundary, Thalamocortical projections, Corticofugal axons, Mouse

\section{INTRODUCTION}

The embryonic forebrain is comprised of distinct domains, prosomeres, each with specific morphological features and gene expression patterns (Puelles and Rubenstein, 1993). Their borders often coincide with changes in the trajectories of axonal pathways (Wilson et al., 1997). TCAs and CFAs have to travel through numerous newly formed subdivisions of the embryonic brain. These critical boundaries outlined by distinct molecular properties (Puelles et al., 2000) include the diencephalon-telencephalon junction and the PSPB. Recent data indicate that some transcription factors are expressed (Pax6, Tbr1, Ngn2, Emx2 and Otx2) or escape (Emx1) the region of the ventral pallium (see Puelles et al., 2000), thus having a modulatory potential for the molecular patterning at the PSPB and the axonal pathfinding.

Early-generated, largely transient neuronal populations, have been described to extend pioneering axonal projections through these critical boundaries, thus providing scaffolds or temporary targets, 'guide-post cells', for the developing axonal projections (McConnell et al., 1989; Mitrofanis and Guillery, 1993). It has been suggested that the early outgrowth of TCAs from the diencephalon might be governed by pioneering projections from cells within the internal capsule (Métin and Godement, 1996), while the crossing of the PSPB by the TCAs might be dependent on selective fasciculation with these corticofugal projections (Molnár and Blakemore, 1995). Recent studies in homeobox gene mutants seem to support these suggestions. In Mashl (Ascll - Mouse Genome Informatics) homozygous mice, the internal capsule cells with thalamic projections are missing and TCAs fail to enter the internal capsule (Tuttle et al., 1999). In Emx2 homozygous mice, the early internal capsule projections take an aberrant ventral route at the diencephalon-telencephalon junction, and some of the TCAs follow them as they traverse that region (López-Bendito et al., 2002). In Tbr1, Gbx2 and Pax6 mutants, both TCAs and CFAs become derailed at the PSPB (MiyashitaLin et al., 1999; Hevner et al., 2001; Hevner et al., 2002), but the nature of these defects is not fully understood.

Pax6 has been found to have an essential role in brain morphogenesis (Walter and Gruss, 1991; Schmahl et al., 1993; Stoykova et al., 1996; Stoykova et al., 1997; Caric et al., 1997; Warren et al., 1999), and has been implicated in early axonal pathfinding (Mastick et al., 1997; Kawano et al., 1999; Pratt et 
al., 2000). A Pax6-positive group of cells was observed to extend along the PSBP, from the ventricular/subventricular zones (VZ/SVZ) towards the mantle of the basal telencephalon (Stoykova et al., 1997; Fernandez et al., 1998; Puelles et al., 2000). Lack of Pax6 function in the Pax6 $6^{\text {Sey/Sey }}$ mutant brains, results in a prominent ventralization of the molecular characteristics of the region of the ventral pallium that leads to severe morphological malformation in the basolateral cortex (Stoykova et al., 2000; Toresson et al., 2000; Yun et al., 2001).

Using a Pax6/lacZ knockout mouse (St-Onge et al., 1997), we studied the consequences of the lack of Pax6 on the TCA and CFA pathfinding with special interest to the axonal navigation within the PSPB. We found that in Pax6-deficient brains, both TCAs and CFAs showed severe malformations of their pathfinding when reaching the PSPB domain and these correlated with ultrastructural defects of this region and a failure of the expression of axonal guidance molecules, such as the attractants Sema3c and Sema5a.

\section{MATERIALS AND METHODS}

\section{Animals}

In the Pax6/lacZ knockout, the start codon and the entire paired domain of Pax6 is replaced with $\beta$-galactosidase sequence, thus placing the activity of this reporter gene under the control of the endogenous Pax6 promoter (St-Onge et al., 1997). Mouse embryos were derived from intercrosses of heterozygous males and females on a mixed background (NMRI and C57BL/6J $\times \mathrm{DBA} / 2 \mathrm{~J}$ ) and the day of vaginal plug was considered as E0.5. Brains were isolated from matched heterozygous and homozygous embryos at stages E14.5, E15.5 and E18.5. This knockout shows phenotype similar as the Pax6 $6^{\text {Sey/Sey }}$ mutation (St-Onge et al., 1997; Hill et al., 1991). The care and handling of the animals prior to and during the experimental procedures followed European Union regulations. Fetuses were removed by Caesarean section under pentobarbital anaesthesia (100 $\mathrm{mg} / \mathrm{kg}$ i.p., to the pregnant female). Embryos were anaesthetized by hypothermia prior decapitation. Embryonic brains were fixed overnight in freshly prepared $4 \%$ paraformaldehyde in $0.1 \mathrm{M}$ phosphate buffer (PB, pH 7.4).

\section{Detection of Pax6 promoter activity}

The expression pattern of Pax6 in the isolated brains from heterozygous and homozygous embryos was analysed by wholemount- $\beta$-gal staining (Gossler and Zachgo, 1993; Stoykova et al., 1988). Stained brains were embedded in $4 \%$ agarose and coronal sections were cut with a Vibroslicer (Leica, VT1000S) at $50 \mu \mathrm{m}$. Sections were mounted on slides in PBS/glycerol, coverslipped and examined with a light microscope. In situ hybridization on wholemounts and in sections was performed with Pax6 in situ probe (Walther and Gruss, 1991) as described elsewhere (Stoykova and Gruss, 1994).

\section{Immunohistochemistry}

E14.5 and E18.5 wild-type, heterozygote and homozygous brains were used (see numbers at Table 1 for each time point). After $\beta$ galactosidase staining of the isolated brains, tissue was embedded in $4 \%$ agarose and sectioned at $40-100 \mu \mathrm{m}$ coronally with a Vibroslicer. Alternatively, after immersion of brains in $30 \%$ sucrose solution overnight at $4{ }^{\circ} \mathrm{C}$, tissue was sectioned coronally at $20 \mu \mathrm{m}$ with a microtome. Immunohistochemistry was carried out with rat anti-L1 (Boehringer, 1:100) and mouse monoclonal anti-TAG1 (Developmental Studies Hybridoma Bank, Iowa; 1:100) antibodies. Sections were incubated overnight with primary antibodies at $4^{\circ} \mathrm{C}$. Primary antibodies were detected by a biotinylated secondary antibody $(1: 100)$ and the avidin-biotin complex (ABC, dilution 1:100) method (Vector). The reaction was visualized using $0.05 \%$ diaminobenzidine solution (Sigma). Sections were rinsed, dehydrated and mounted in Eukitt mounting media. To study cytoarchitecture, sections were treated with $0.5 \%$ Cresyl Violet solution. Sections were visualized by light microscopy and documented with a Leica DC500 digital camera.

\section{Axonal tracing with carbocyanine dyes}

Brains at E14.5, E15.5 and E18.5 were fixed overnight in $4 \%$ paraformaldehyde (see Table 1). To expose the dorsal thalamus, a coronal cut was made at the caudal edge of the diencephalon. The zona limitans intrathalamica provided the landmark for orientation. Single crystals of DiI (1, 1- dioctadecyl -3, 3, 3',3'-tetramethylindocarbocyanine perchlorate; Molecular Probes), and of DiA [4(4-(dihexadecylamino)styryl)-N-methylpyridium iodide; Molecular Probes], were placed with a fine tungsten wire into the dorsal thalamus or dorsal cortex under a dissecting microscope. Brains were incubated in $4 \%$ paraformaldehyde at room temperature (RT) for 3 weeks. The brains were then embedded in $4 \%$ agarose and $100 \mu \mathrm{m}$ coronal Vibroslicer sections were cut. Tissue was counterstained with $0.002 \%$ bisbenzimide. Sections were coverslipped in 1:1 mixture of PB and glycerol and analysed with a fluorescent microscope (Leica DMR) or a laser scanning confocal microscope (Leica TCS).

\section{Electron microscopy}

Four E15.5 mice and four E18.5 mice (two Pax6 $6^{-/-}$and two Pax6 $6^{+/+}$ brains for each age) were used. Brains were immersed overnight in ice-cold fixative containing $2 \%$ paraformaldehyde and $2 \%$ glutaraldehyde in $0.1 \mathrm{M}$ phosphate buffer ( $\mathrm{PB}, \mathrm{pH}$ 7.2-7.4). Tissue blocks were dissected and washed in $0.1 \mathrm{M} \mathrm{PB}$. Coronal $60 \mu \mathrm{m}$ sections of the telencephalon were cut with a Vibroslicer. After several washes in $0.1 \mathrm{M} \mathrm{PB}$, selected sections were treated with $\mathrm{OsO}_{4}(1 \%$ in $0.1 \mathrm{M} \mathrm{PB}$ ), block-stained with uranyl acetate, dehydrated in a graded series of ethanols and flat-embedded on glass slides in Durcupan (Fluka) resin. Ultrathin sections (60 to $80 \mathrm{~nm}$ ) from selected areas of the telencephalon were picked up on coated copper grids. The grids were counterstained with saturated aqueous uranyl acetate followed by lead citrate. The sections were examined with a Joel (JEM 1010) transmission electron microscope.

\section{In situ hybridization}

In situ hybridization experiments were performed using ${ }^{35} \mathrm{~S}$ riboprobes on $10 \mu \mathrm{m}$ frozen sections from E14.5 and E18.5 brains (see Table 1) according to standard protocols described previously (Stoykova et al., 2000). The cDNA probes were for Sema3a, Sema3c, Sema5A, Sema5b, Sema6a and netrin 1 (gifts from A. Puschel and M. Tessier-Lavigne).

\section{RESULTS}

\section{lacZ expression pattern in Pax6 transgenic embryos}

The expression pattern seen in E12.5 wild-type embryos after whole-mount in situ hybridization with Pax6 probe (Fig. 1A) and the pattern seen in Pax6 homozygous embryos with $\beta$ galactosidase staining (Fig. 1B) were very similar. This indicated that the $\beta$-galactosidase activity in the transgenic embryos correctly reflected the well-characterized expression pattern of Pax6 in developing mouse CNS (St-Onge et al., 1997). However, we detected a wider $\beta$-gal staining pattern in the pallium of the transgenic embryos that included expression not only in cortical progenitors, but also in postmitotic cells of the cortical plate. Such a discrepancy between the normal distribution of mRNA and the $\beta$-gal staining pattern in 


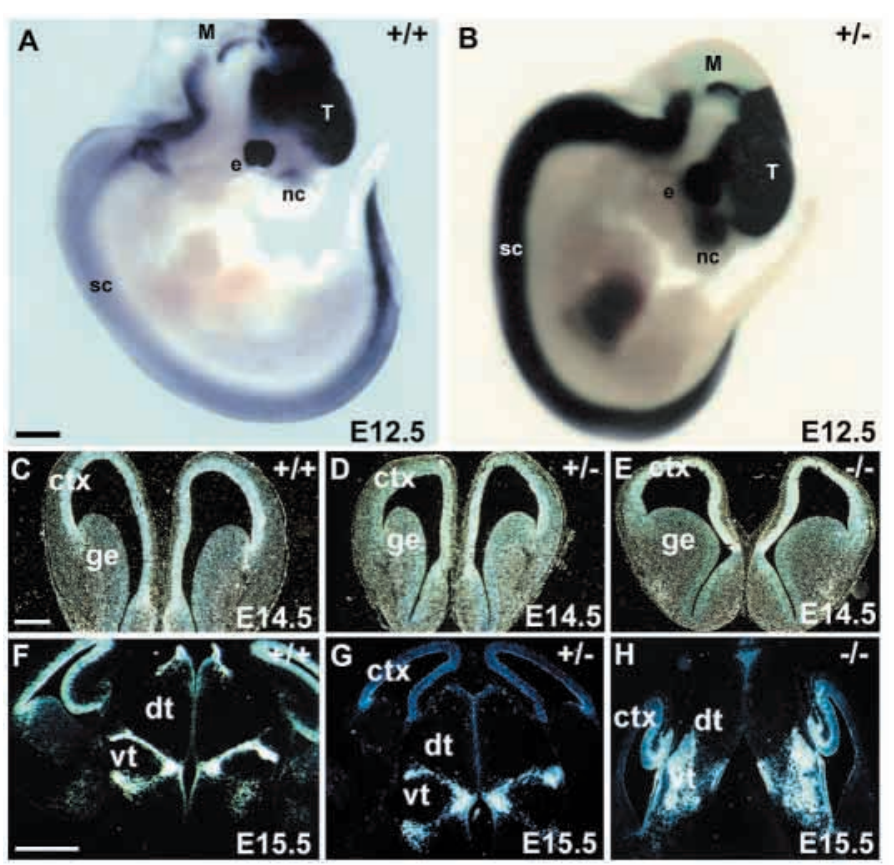

transgenic animals was accounted for by the longer half-life of the $\beta$-galactosidase protein when compared with the transcript (see Scardigli et al., 2001). We examined the endogenous expression of Pax6 using the Pax6 in situ probe in wild-type brain sections and the lac $Z$ in situ probe in sections from heterozygous and homozygous embryonic brains to investigate this further. In sections of E14.5 wild-type (Fig. 1C), heterozygous (Fig. 1D) and homozygous Pax6 $^{-1-}$ (Fig. 1E) brain, the hybridization signals for Pax6 (Fig. 1C) and lacZ (Fig. 1D,E) were confined only to the germinal neuroepithelium (VZ/SVZ) of the pallium. In accordance with the previously reported analysis for homozygous $\mathrm{Paxb}^{\mathrm{Sey} / \mathrm{Sey}}$ brains (Stoykova et al., 1997; Stoykova et al., 2000), the prominent expression of lac $Z$ at the PSPB faded in the
Fig. 1. lacZ expression correctly reflects the activity of the endogenous Pax6 promoter in the proliferative neuroepithelium in the Pax6 $^{-1-}$ mice. $(\mathrm{A}, \mathrm{B})$ Whole-mount in situ hybridization analysis for Pax6 (A) and $\beta$-gal (B) staining of E12.5 wild-type (+/+) and heterozygous (+/-) transgenic embryos show similar distribution of the signal in the developing CNS and eye. (C-E) The in situ hybridization analysis with probes for Pax6 (C) or lacZ (D,E) genes in wild-type (C) and heterozygous (D) and homozygous (E) transgenic forebrains, reveals similar expression pattern confined to the proliferative neuroepithelium of the dorsal telencephalon. $(\mathrm{F}-\mathrm{H})$ At stage E15.5, similar expression is seen for Pax6 in differentiating nuclei of ventral thalamus by the in situ probes for Pax6 (F) or lacZ $(\mathrm{G})$ in the wild-type and heterozygous embryos, respectively. $(\mathrm{H}) \mathrm{In}$ homozygous embryos, the differentiation of the ventral thalamic nuclei as revealed by the lac $Z$ expression pattern fails. dt, dorsal thalamus; vt, ventral thalamus; ctx, cortex; ge, ganglionic eminence; nc, nasal cavity; e, eye; T, telencephalon; M, mesencephalon; sc, spinal cord. Scale bars: $1 \mathrm{~mm}$ in A,B; $200 \mu \mathrm{m}$ in C-E; $500 \mu \mathrm{m}$ in F-H.

transgenic homozygous brains (Fig. 1E). Furthermore, a very similar expression was detected by the Pax6 and lacZ in situ probes in differentiating nuclei within the ventral thalamus (VT) of the wild-type (Fig. 1F) and heterozygous (Fig. 1G) brains. With these experiments, we excluded the possibility that, in the transgenic embryos, some regulatory sequences that are responsible for the regionalized expression of Pax6 in the pallial VZ/SVZ were missing. We concluded, therefore, that the lacZ expression pattern in the $\mathrm{Pax}^{-/-}$mice correctly represented the endogenous Pax 6 expression pattern in the developing telencephalon.

\section{Aberrant thalamocortical axonal projections in the Pax6 $^{-/}$forebrain}

In order to study axonal pathway formation in the $\operatorname{Pax6}^{-/-}$, we used carbocyanine dyes to trace TCAs in fixed brains (see Table 1). DiI crystal placement into dorsal thalamus from E14.5 to E18.5 in wild-type brains labelled TCAs extending to the primitive internal capsule having a normal fasciculation

Table 1. Breakdown of the number of animals studied

\begin{tabular}{|c|c|c|c|c|}
\hline \multirow[b]{2}{*}{ Treatment } & \multicolumn{4}{|c|}{ Genotype } \\
\hline & Age & Pax6/lac $Z^{+/+}$ & Pax6/lac $Z^{+/-}$ & Pax6/lac $Z^{-/-}$ \\
\hline $\begin{array}{l}\text { Whole-mount in situ with Pax6 and lacZ } \\
\text { lacZ and Pax6 in situ hybridization }\end{array}$ & $\begin{array}{l}\text { E12.5 } \\
\text { E14.5 } \\
\text { E15.5 }\end{array}$ & $\begin{array}{l}2 \\
1 \\
1\end{array}$ & $\begin{array}{l}2 \\
1 \\
1\end{array}$ & $\begin{array}{l}2 \\
1 \\
1\end{array}$ \\
\hline Nissl staining & $\begin{array}{l}\text { E14.5 } \\
\text { E15.5 } \\
\text { E18.5 }\end{array}$ & $\begin{array}{l}2 \\
2 \\
2\end{array}$ & $\begin{array}{l}2 \\
2 \\
2\end{array}$ & $\begin{array}{l}2 \\
2 \\
2\end{array}$ \\
\hline Carbocyanine dye tracing & $\begin{array}{l}\text { E14.5 } \\
\text { E15.5 } \\
\text { E18.5 }\end{array}$ & $\begin{array}{l}5 \\
8 \\
8\end{array}$ & $\begin{array}{l}8 \\
8 \\
8\end{array}$ & $\begin{array}{l}4 \\
7 \\
9\end{array}$ \\
\hline L1 and TAG1 immunohistochemistry & $\begin{array}{l}\text { E14.5 } \\
\text { E18.5 }\end{array}$ & $\begin{array}{l}7 \\
7\end{array}$ & $\begin{array}{l}8 \\
8\end{array}$ & $\begin{array}{c}8 \\
13\end{array}$ \\
\hline$\beta$-Galactosidase staining & \multicolumn{4}{|c|}{$\begin{array}{l}\text { The brains used for carbocyanine tracing and immunohistochemistry were all } \\
\text { stained }\end{array}$} \\
\hline Electron microscopy & $\begin{array}{l}\text { E15.5 } \\
\text { E18.5 }\end{array}$ & $\begin{array}{l}2 \\
2\end{array}$ & $\begin{array}{l}\text { None } \\
\text { None }\end{array}$ & $\begin{array}{l}2 \\
2\end{array}$ \\
\hline $\begin{array}{l}\text { In situ hybridization for axonal guidance } \mathrm{r} \\
\text { Sema5a, Sema5b, Sema6a, netrin 1) }\end{array}$ & E14.5 & 2 & 2 & 2 \\
\hline
\end{tabular}



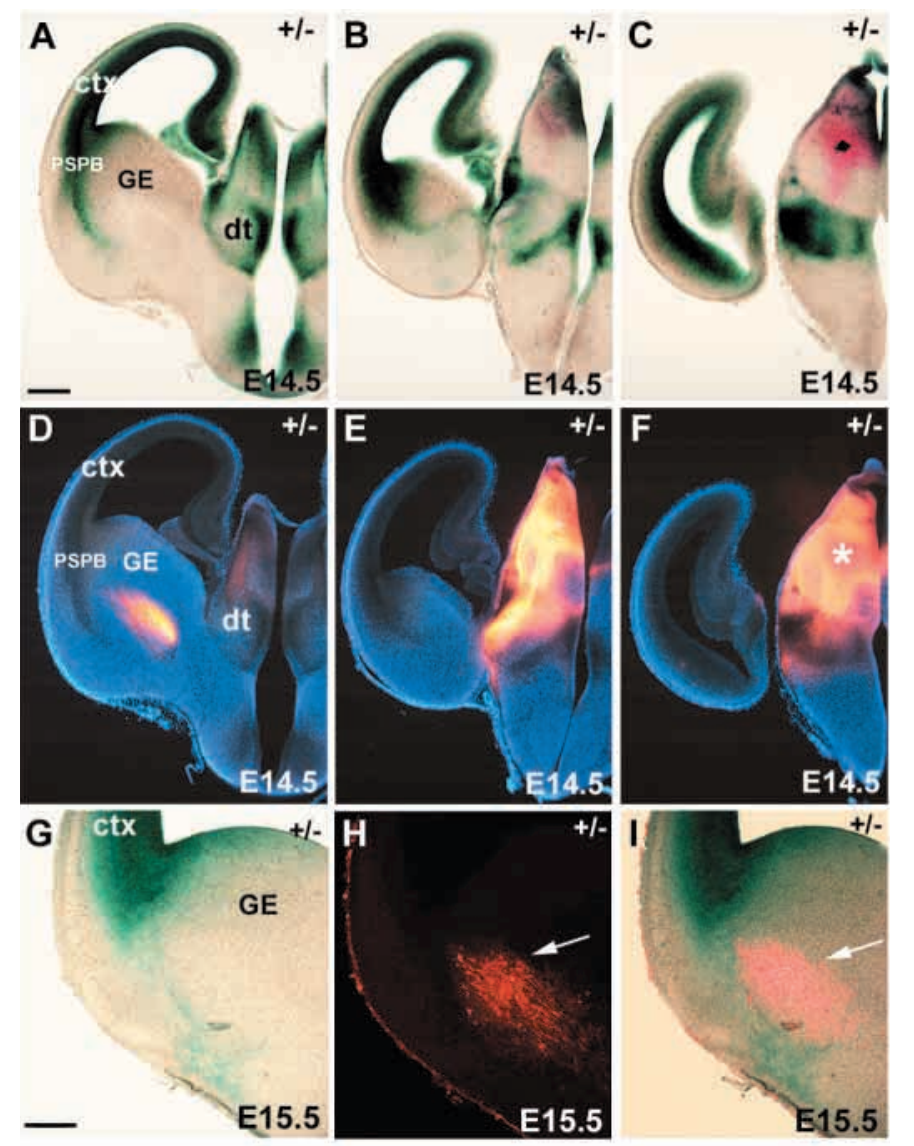

Fig. 2. The precise anatomical correlation between $\beta$-galactosidase staining, which reflects Pax6 in situ hybridization pattern, and the trajectory of the developing TCAs were studied in E14.5 (A-F) and E15.5 (G-I) $P a x 6^{+-}$brains. A single DiI crystal was placed into the dorsal thalamus (dt) (asterisk in F) of $\operatorname{Pax}^{+/-}$brains after they had been stained with $\beta$-galactosidase. From the E14.5 brain, three adjacent serial sections were examined with light microscopy for $\beta$ galactosidase expression, which appears green-blue (A-C), and with two filters of a fluorescent microscope to reveal the DiI-labelled thalamic fibres (red) and the bisbenzimide counterstaining (blue) on superimposed images (D-F). (D-F) The TCAs crossed the diencephalic-telencephalic boundary (E) and extended through the internal capsule (D). By E15.5 (G-I), labelled cells were observed in the internal capsule (arrow in H). (I) On the superimposed image of $\mathrm{G}$ and $\mathrm{H}$, note that the $\beta$-galactosidase staining extends lateral to the group of backlabelled internal capsule cells (arrow in I). ctx, cerebral cortex; GE, ganglionic eminences; PSPB pallial/subpallial boundary. Scale bars: $200 \mu \mathrm{m}$ in A-F; $100 \mu \mathrm{m}$ in G-I.

pattern (see Fig. 3A,B). This was also seen in heterozygous brains (Fig. 2D). DiI crystal placements in the dorsal thalamus revealed a group of cells within the internal capsule, which were situated medial to the $\beta$-galactosidase stained stripe of cells at the PSPB (Fig. 2G-I). It is known that some cells of the internal capsule project to dorsal thalamus (Métin and Godement, 1996; Molnár et al., 1998). However, in the homozygous brains, only a few backlabelled cells were seen at the ventral telencephalon along the predicted trajectory of the TCA pathway (Fig. 3I,J), but many were observed located the hypothalamus (Fig. 3F-H).

As it has been suggested that TCA development is delayed in the lack of Pax6 (Pratt et al., 2000), we examined TCA development in the Pax6 $^{-1-}$ at E15.5 and E18.5. In the E15.5 brains, TCAs projected from the dorsal thalamus to the hypothalamus (Fig. 3E-G) and by E18.5, some TCAs reached the ventral telencephalon (Fig. 3K,L) from where they ascended dorsally towards the ganglionic eminences, following an aberrant trajectory. Although they could be followed towards the PSPB, they were not able to cross it to enter into the cortex (Fig. 4Q).

\section{Corticofugal axonal projections are disrupted in the Pax6 knockout forebrain}

We then examined whether the ability of CFAs to navigate across the PSPB was affected in the $\mathrm{Pax}^{-{ }^{--}}$brains. In wild-type and heterozygotes mice at E14.5 and E15.5, CFAs extended through the intermediate zone to reach the PSPB, displaying a normal fasciculation pattern (Fig. 4A,B). In the Pax6 $^{-1-}$ brains, CFA tracing studies revealed several abnormalities. At E15.5, the CFA pathway started to descend towards the PSPB, but it was displaced laterally (Fig. 4C,D). At later stages, large numbers of axons were seen to course ventrolaterally through the developing lateral pallium, extending towards the base of the ventral pallium (the amygdaloid region) (Fig. 4H). The majority of CFAs were unable to change their trajectories to cross the PSPB (Fig. 4J), nevertheless some entered into the subpallium fasciculating abnormally in large bundles at more caudal levels (Fig. 4K-M). We observed more numerous backlabelled cells in the marginal zone distant from the cortical crystal placement sites in the mutants, suggesting that they developed long range projections (Fig. 4N). The callosal projections were present in the mutants, but their fasciculation pattern was also abnormal (Fig. 4O). Cortical placement of DiI crystals in wild-type brains at E15.5 revealed continuous axonal bundles (Fig. 4F), which extended to groups of backlabelled cells in the dorsal thalamus (data not shown) (see Molnár et al., 1998). As carbocyanine dyes travel in both anterograde and retrograde directions in fixed tissue, and thalamic fibres arrive to the cortex by E15.5, the bundles labelled at E18.5 contained both sets of fibres. In the $P a x 6^{-I-}$ brains, however, we did not observe backlabelled groups of cells in the dorsal thalamus after cortical crystal placements, and we could not detect any interaction between CFAs and TCAs when we used double labelling (Fig. 4Q,S,U). This confirmed our observation obtained with anterograde tracing from the thalamus, and indicated that, although thalamic axons approached the PSPB, they did not reach the cortex in the mutants.

\section{L1 expression and detection of thalamocortical axons}

To examine the gross pattern of TCA growth, we performed L1 immunohistochemistry. Interestingly, we observed that L1 expression was not limited only to TCAs at stage E14.5 and E18.5 as previously thought (Fukuda et al., 1997), but L1 immunoreactive fibres were present in dorsal cortex at E14.5 (Fig. 5A,B). At this stage, TCAs normally extend only to the level of the PSPB and do not invade the intermediate zone of the cortex (De Carlos and O'Leary, 1992; Erzurumulu and Jhaveri, 1992). Therefore, the detected immunoreactivity for L1 in the cortex at this age cannot be due the presence of TCAs, suggesting that the CFAs were also labelled as they extend in the intermediate zone of the dorsal cortex towards the PSPB.

TCAs and CFAs are known to reach the PSPB 

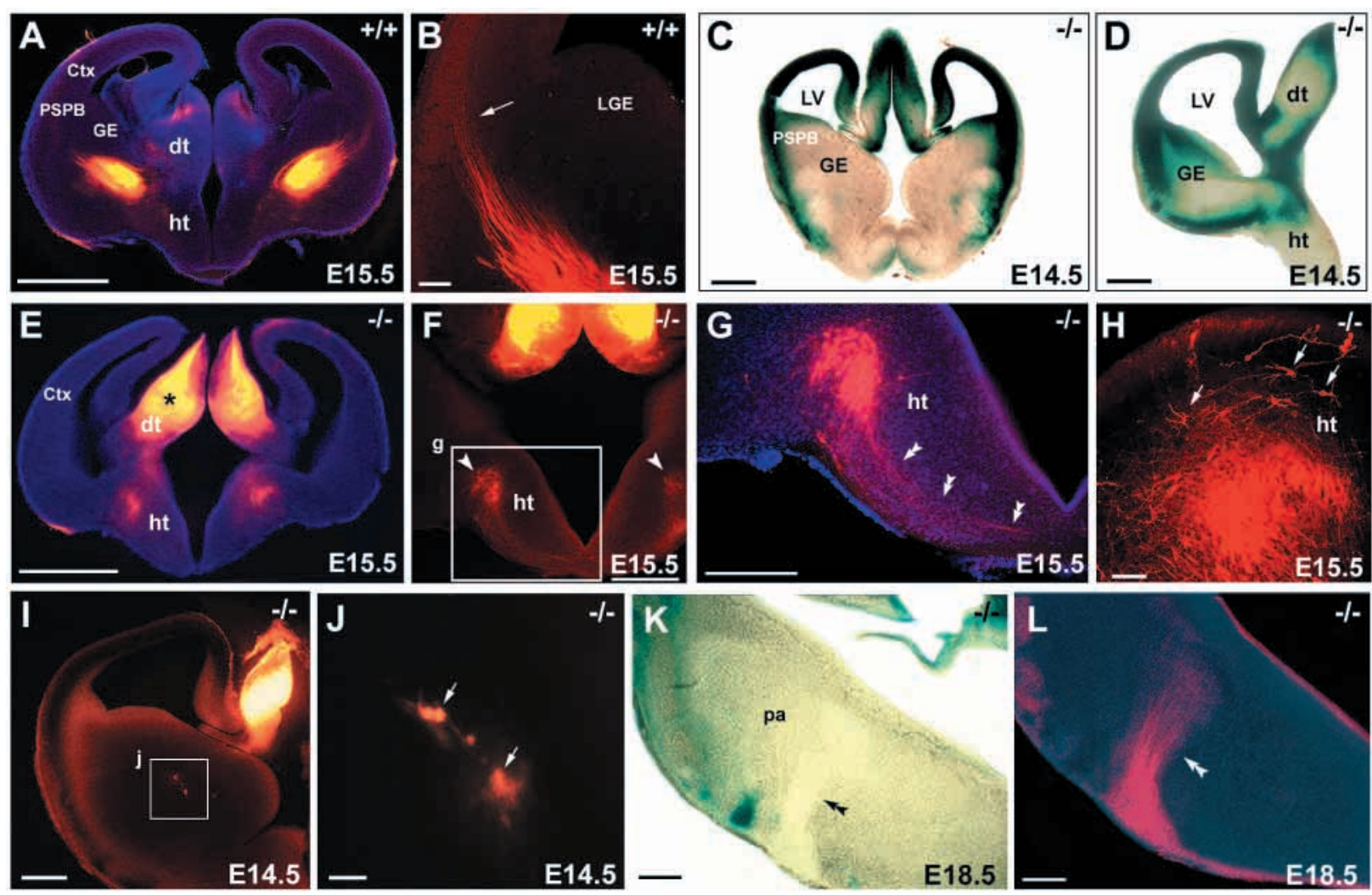

Fig. 3. Alterations of the early thalamocortical projections in Pax6 $6^{-1-}$ mice. (A,B) After dorsal thalamic (dt) DiI placements in both hemispheres at E15.5, TCAs were observed extending through the internal capsule (A), reaching the intermediate zone of the dorsal cortex (ctx) (arrow in B). (C,D) Two coronal sections stained for $\beta$-galactosidase in an E14.5 Pax $^{-1-}$ mouse. Note the altered staining in ventral and lateral telencephalic areas compared with heterozygous brains shown in Fig.2A-C. (E,F) Dorsal thalamic DiI crystal placement in the Pax6 ${ }^{-1-}$ brains (asterisk in E) showing that the ventrolateral hypothalamus (ht) was invaded by TCAs (E; arrowheads in F). (G) High power image of the box indicated in F. TCAs were observed crossing to the contralateral ventral hypothalamus (double arrowheads in G). (H) Backlabelled cells were also observed in abnormal locations in the hypothalamus (arrows in H). (I) Dorsal thalamic DiI crystal placement revealed few backlabelled cells within the internal capsule. (J) High-power image from the region indicated with the box in I (arrows indicate labelled cells). (K,L) By E18.5, TCAs in the Pax6 $6^{--}$emerged abnormally from the base of the ventral telencephalon (double arrowheads). GE, ganglionic eminences; pa, pallium; LGE, lateral ganglionic eminence; LV, lateral ventricle; PSPB, pallial/subpallial boundary. Scale bars: $400 \mu \mathrm{m}$ in A,E; $100 \mu \mathrm{m}$ in $\mathrm{B}, \mathrm{G}, \mathrm{H}, \mathrm{I}, \mathrm{K}, \mathrm{L} ; 200 \mu \mathrm{m}$ in $\mathrm{C}, \mathrm{D}, \mathrm{F} ; 20 \mu \mathrm{m}$ in $\mathrm{J}$.

synchronously (De Carlos and O'Leary, 1992) and the two sets of axons intermingle (Molnár et al., 1998). By E18.5 in wildtype brains, TCAs have reached to the cortex through the intermediate zone (Catalano et al., 1991). L1 immunolabelling in wild-type sections (Fig. 5E,I) revealed the gross organization of the fascicles in the striatum, PSPB and in the intermediate zone. In $\operatorname{Pax}^{-/-}$, L1 immunoreactivity was detected on both CFAs and TCAs at the two studied ages (Fig. 5C,G) and at E14.5, TCAs were seen emerging from the basal ventral telencephalon and had turned dorsomedially towards the subventricular zone of the ganglionic eminence, but did not cross the PSPB (Fig. 5C,D). At E18.5, in Pax6 ${ }^{-/-}$brains, L1 immunolabelled fibres reached the PSPB, but they could not be followed crossing this boundary (Fig. 5F,G,J,K). The L1positive fibre trajectory of CFAs in the cortex was displaced ventrolaterally and axons continued their path to the ventral pallium as if they were unable to cross the PSPB (Fig. 5D). As described above with carbocyanine dyes (Fig. 4Q), using immunohistochemistry for L1 we described similar results which point out that TCAs and CFAs failed to meet each other at the PSPB.

\section{TAG1 expression and corticofugal axons}

CFAs selectively express the cell adhesion molecule TAG1 (Denaxa et al., 2001). The immunostaining for TAG1, however, seemed to reveal only the initial part of this pathway, as TAG1 immunoreactivity was drastically reduced at the level of PSPB (see López-Bendito et al., 2002). In the wild-type forebrain at E14.5, TAG1 immunoreactive CFAs appeared to extend through the intermediate zone of the developing pallium to reach the PSPB (Fig. 5M,N). At E18.5, TAG1 immunoreactivity was expressed primarily by cells of the cortical plate and marginal zone in the hippocampus and corpus callosum (not shown). In the Pax6 $^{---}$brains, TAG1 immunoreactive fibres followed aberrant trajectories, being displaced laterally in thick bundles (Fig. 5O,P). In addition, TAG1 expression in cortical plate and marginal zone was reduced, preserved mostly within the medial pallium. These findings were consistent with the abnormalities observed in CFA development in $\mathrm{Pax}^{-/-}$with DiI tracing.

\section{Abnormalities at the PSPB in the $\mathrm{Pax6}^{-/-}$brain}

We further examined the cellular organization of the PSPB 

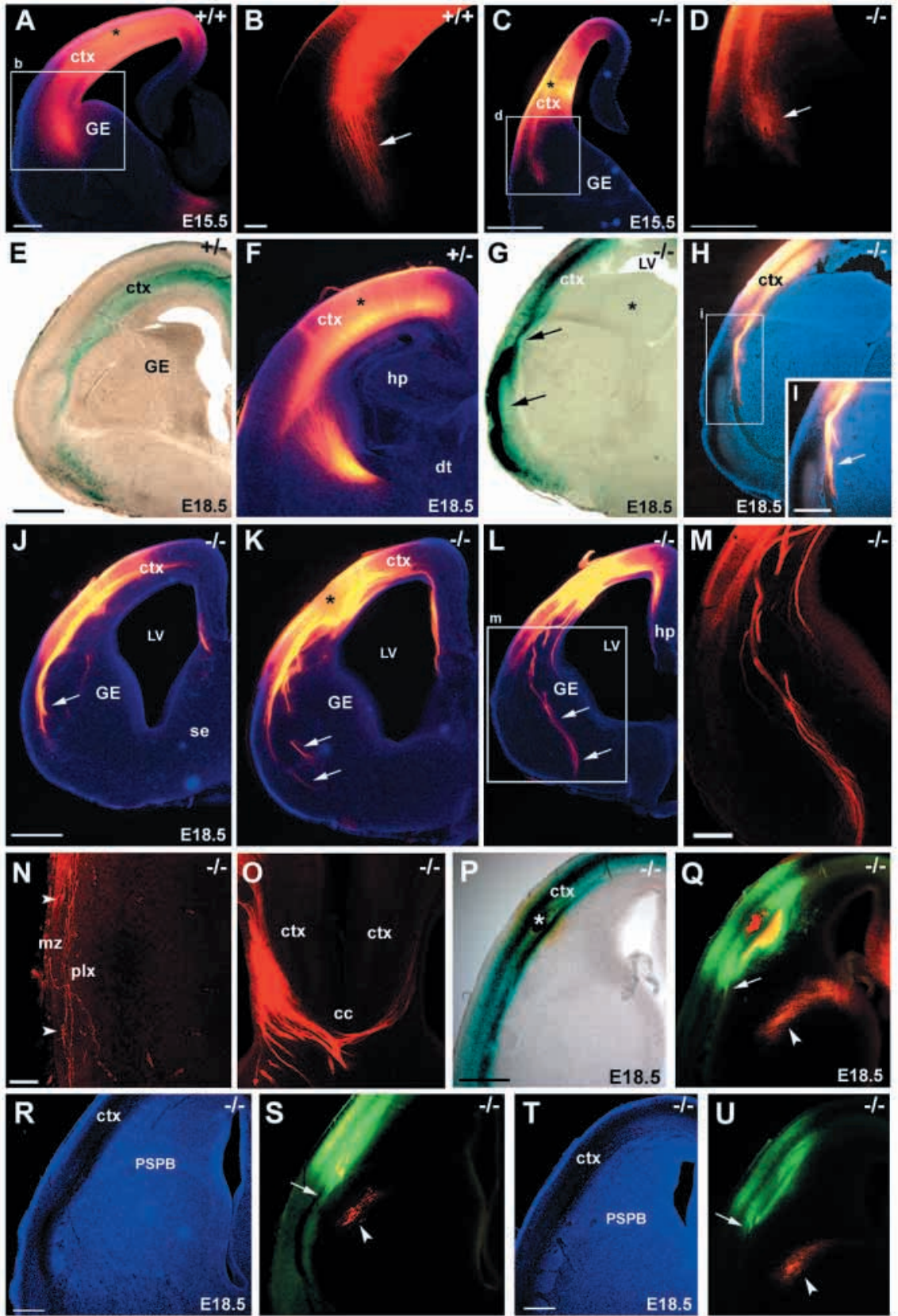

Fig. 4. Defects in CFAs in the Pax6 $6^{-/}$brains revealed by tracing with carbocyanine dyes. (AD) Early CFA were labelled from single DiI crystal placement in the dorsal cortex (ctx) (asterisks in A and C) of an E15.5 wild-type (A,B) and Pax6 $6^{-1-}$ brain (C,D). CFA in both phenotypes descend through the intermediate zone and turn towards the primitive internal capsule (arrows in B,D). (E) $\beta$-galactosidase staining in a coronal section of an E18.5 $\mathrm{Pax}^{+/-}$ brain. (F) Trajectories of fibres labelled from cortical DiI placement (asterisk) in a similar section to that shown in E, of an E18.5 $\mathrm{Pax}^{+/-}$ brain. (G) $\beta$-galactosidase staining is displaced ventrolaterally in the PSPB (arrows) in the $\mathrm{Pax6}^{-/-}$brain. Note the presence of an abnormal cellular mass (asterisk) protruding into the lateral ventricle $(\mathrm{LV})$. (H) Same section as $\mathrm{G}$ showing the abnormal pathway of CFA in $\operatorname{Pax}^{-1-}$ brains. (J-M) Coronal sections from more rostral (J) to more caudal (L) levels, showing abnormal CFA in an E18.5 Pax6 $^{-/-}$brain. (M) High-power image from the region indicated by the box in $\mathrm{K}$. Some fibres descend towards the ventral pallium and cross the PSPB at a more ventral position in large fascicles (arrows in J-L). (N) Numerous backlabelled cells are seen in the marginal zone (mz) of the paleocortex (plx) (arrowheads),

suggesting that they develop abnormal projections to the tracing site. $(\mathrm{O})$ Fibres of the corpus callosum (cc) labelled by cortical DiI crystal placements. (P-U) Adjacent serial sections from an E18.5 Pax6 $^{--}$brain in which double

carbocyanine dyes were placed, DiA in the cortex and DiI in the dorsal thalamus. Note that the two sets of fibres failed to encounter each other at the PSPB (arrowheads indicate DiI-labelled TCAs, and arrows indicate DiA-labelled CFA in Q,S,U). (P) $\beta$-Galactosidase staining of the section shown in $\mathrm{Q} ;(\mathrm{R}, \mathrm{T})$ The bizbenzimide staining of sections in $S, U$, respectively. GE, ganglionic eminence; cc, corpus callosum; se, septal eminence; hp, hippocampus; dt, dorsal thalamus. Scale bars: 200 $\mu \mathrm{m}$ in $\mathrm{A}, \mathrm{C}, \mathrm{I} ; 100 \mu \mathrm{m}$ in $\mathrm{B}, \mathrm{D}, \mathrm{N}, \mathrm{M}, \mathrm{O} ; 400 \mu \mathrm{m}$ in E-H,J-L,P,Q domain in relation to the $\beta$-galactosidase staining in the developing forebrain of E14.5 and E18.5 heterozygous and homozygous embryos. In E14.5 $\mathrm{Pax6}^{-1-}$ brains, the telencephalic neuroepithelium at the PSPB appeared broader and more irregular compared with normal, and consisted of aggregated cells which were heavily stained with Cresyl Violet (Fig. 6D-F). By E18.5, a considerable cell mass was prominent, which often occluded most of the lateral ventricle at rostral level (Fig. 5F,G). The extended region consisted of cells that were heavily stained for Nissl but negative for $\beta$-galactosidase stain. These cells were densely packed together and appeared to be continuous with the cortical ventricular zone. The thickened pallial germinal neuroepithelium of the E18.5 Pax6 $^{-1-}$ was also $\beta$-galactosidase negative (Fig. 4G, Fig. 5F,G,K). In the $\operatorname{Pax}^{-{ }^{-}-}$, the ventricular cellular mass and the atypical PSPB did not show immunoreactivity for the glial cell markers GFAP or vimentin, and did not express calbindin or GABA, but were immunoreactive for the neuronal marker, $\beta$ tubulin class III (Menezes and Luskin, 1994) (data not shown), suggesting that they comprised undifferentiated neurones. In Pax $^{-1-}$ brains, $\beta$-galactosidase staining of the dorsal cortex continued to the ventral pallium at the lateral surface (Fig. 4G), whereas in heterozygotes the unstained lateral cortex occupied this zone and the $\beta$-galactosidase staining formed a narrow stripe linking stained cells of the amygdala to the cortex (Fig. 4E). In addition, Nissl staining revealed that the cortical plate was drastically reduced in the ventral-most lateral pallium in the Pax $^{-1-}$ brains (Fig. 6F).

\section{Ultrastructural characterization of the wild type and Pax6 $^{-/}$pallium and PSPB at E15.5 and E18.5}

In order to characterize further the morphological 
abnormalities seen in the $\operatorname{Pax}^{-1-}$ mouse, which cause severe disruption in the development of CFAs and TCAs at the PSPB, we performed electron microscopic analysis at that boundary in wild-type and homozygous brains at two different stages, E15.5 and E18.5. In wild-type brains, heterogeneous cell populations within the region of this boundary were observed.
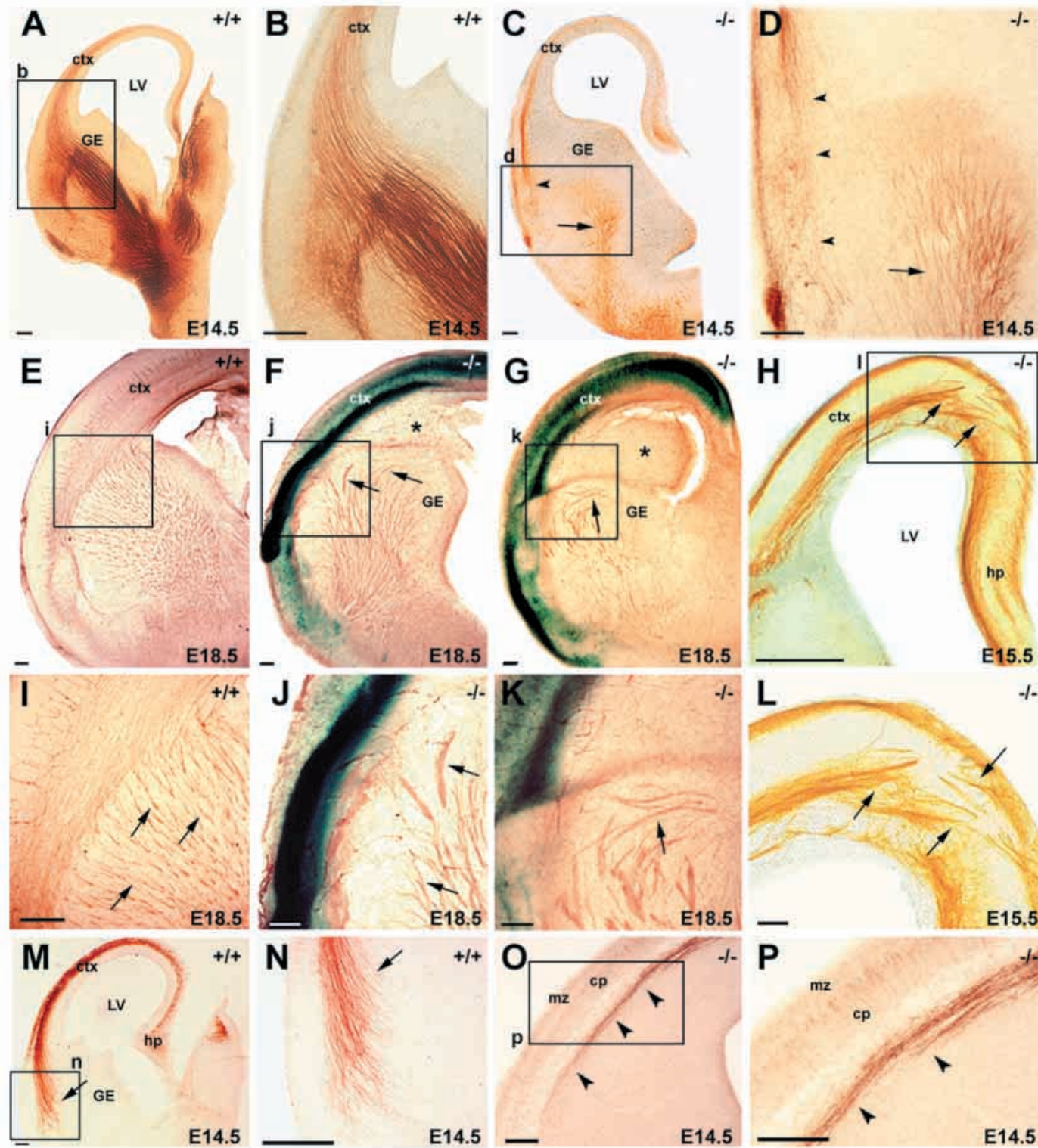
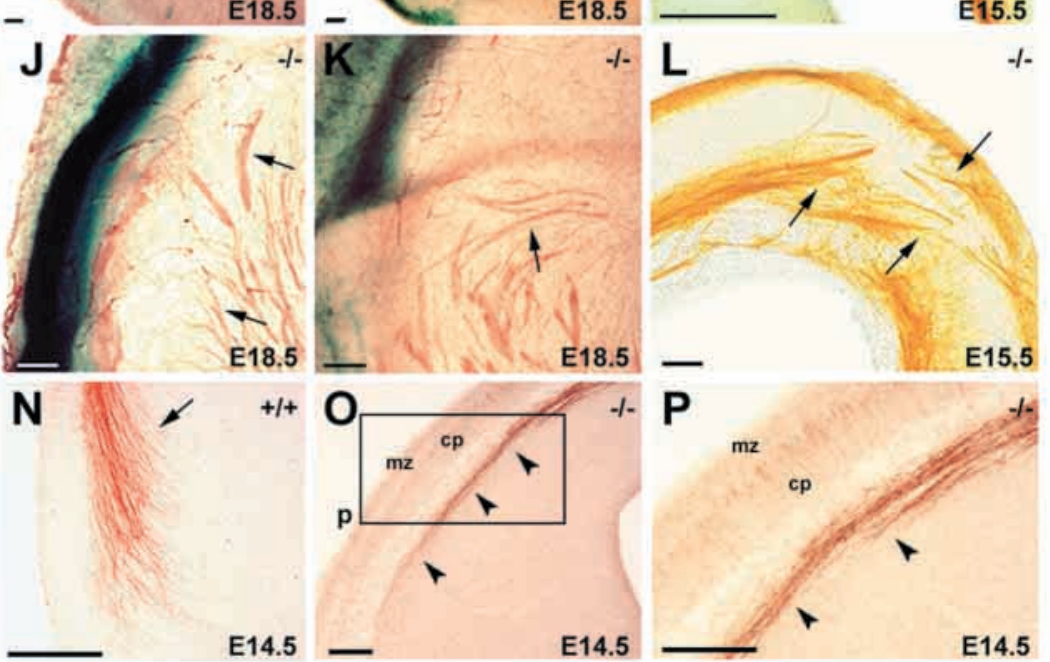

E14.5
Fig. 5. Immunolabeling for L1 (A-L) and TAG1 (M-P) reveals defects in TCAs and CFA in the Pax6 $^{-I}$ brains. (A,B) At E14.5 in wild-type brains, TCAs and CFA are both immunoreactive for $\mathrm{L} 1$ through the internal capsule into the intermediate zone of the cortex (ctx). (C,D) At E14.5 in the Pax6 $^{-1-}$, TCAs (arrows) and CFA (arrowheads) are both aberrant, thalamic axons fail to extend towards the cortex and CFA fail to turn towards the internal capsule. (E,I) At E18.5, L1-positive fibres are observed crossing the PSPB in wild-type brains (arrows in I). $(\mathrm{F}, \mathrm{G}, \mathrm{J}, \mathrm{K}) \mathrm{L} 1$

immunoreactive fibre trajectories follow aberrant pathways and cannot cross the PSPB (arrows) in the $\mathrm{Pax6}^{-1-}$. A cellular mass (asterisk) fills the lateral ventricle $(\mathrm{LV})$. $(\mathrm{H}, \mathrm{L})$

Abnormal fasciculation of L1 immunopositive axons along the dorsal cortex of the Pax6 $^{-1-}$. $(\mathrm{M}, \mathrm{N})$ At E14.5 wild-type brains, TAG1 immunoreactive CFA extend to the PSPB (arrows). (O,P) TAG1 immunoreactive CFA in the $\mathrm{Pax}^{-/-}$cortex (arrowheads) do not cross the PSPB. GE, ganglionic eminences; hp, hippocampus. Scale bars: $100 \mu \mathrm{m}$.
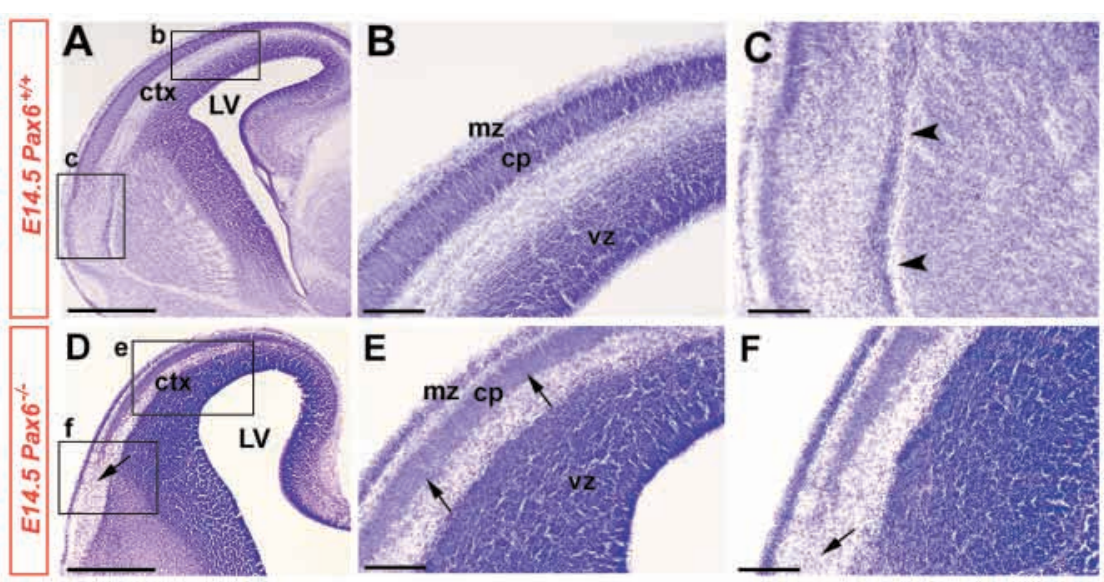

Fig. 6. Morphological defects in the developing telencephalon of the $\mathrm{Pax}^{-1-}$ mice revealed with Nissl staining. (A-C) Nissl-stained coronal section of an E14.5 wild-type brain showing a normal cortical lamination (B) and the morphology of the PSPB (arrowheads in C). (D-F) In Pax6 $6^{-l-}$ brain, an expanded ventricular zone (vz) and a thinner cortical plate (cp) (arrows in E) was observed. Note the absence of $\mathrm{cp}$ in the lateral pallium (arrow in F). ctx, cerebral cortex; LV, lateral ventricle; mz, marginal zone. Scale bars: $200 \mu \mathrm{m}$ in $\mathrm{A}, \mathrm{D} ; 100 \mu \mathrm{m}$ in $\mathrm{B}, \mathrm{C}, \mathrm{E}, \mathrm{F}$. 
Axons crossing the PSPB were seen at E15.5 as well at E18.5 (Fig. 7E,O). However in the Pax6 $6^{-1-}$ brains, the cells within the PSBP domain appeared to be more densely packed than in wild-type brains. This abnormality was more prominent at later stages (Fig. 7H,S). Cells located in this area were seen tightly attached to neighbouring cells (Fig. 7I). In accordance with previous data (Stoykova et al., 1997) and our tracing experiments described above, a few axonal tracts were

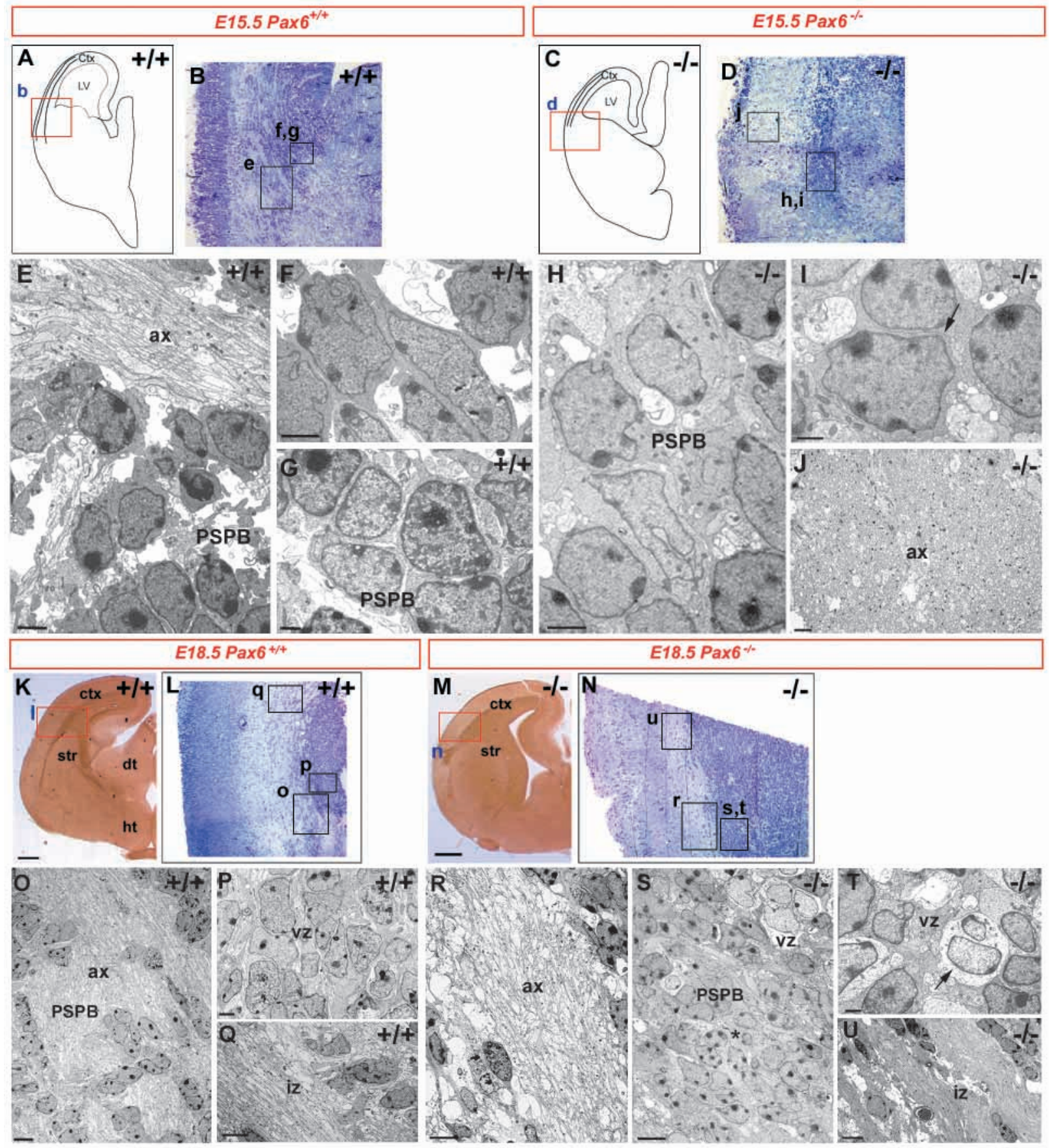

Fig. 7. Ultrastructure of the PSPB in wild-type and $\mathrm{Pax}^{-1-}$ brains at E15.5 (A-J) and E18.5 (K-U). Electron microscopy was performed in coronal sections of wild-type (E-G,O-Q) and $\operatorname{Pax6}^{-I-}$ (H-J,R-U) brains. Boxes on the camera lucida drawings (A,C), in the light microscopy images of resin-embedded sections $(\mathrm{K}, \mathrm{M})$ and in the Toluidine Blue-stained semithin sections $(\mathrm{B}, \mathrm{D}, \mathrm{L}, \mathrm{N})$ indicate the areas examined. (E-G,O-Q) At E15.5 and E18.5, wild-type axons (ax) are observed at the level of the intermediate zone (iz) of the cortex (ctx) (Q) and crossing the PSPB (E,O). (F,G) Higher magnifications of wild-type PSPB cells. (P) High-power view showing the ultrastructure of the ventricular zone (vz) in wild-type brains. (H-J,R-U). At both ages, the lateral telencephalon of the Pax6 ${ }^{-1-}$ brain was abundant in axon bundles (J,R) and less of them are seen crossing the PSPB $(\mathrm{H}, \mathrm{S})$ (compare with E or O). The ultrastructure of the PSPB is characterized by densely packed cells in the Pax6 $^{-1-}$ brains $(\mathrm{H}, \mathrm{S})$. This ultrastructural abnormality was more evident at E18.5 than at early stages (asterisk in S). (T) Clusters of abnormal cells with loss of organelles on the cytoplasm are observed at the vz in Pax $6^{-1-}$ brains at both ages. str, striatum; dt, dorsal thalamus; ht, hypothalamus. Scale bars: $400 \mu \mathrm{m}$ in A,C,K,M; $2 \mu \mathrm{m}$ in E-F,J; $3 \mu \mathrm{m}$ in H; $1 \mu \mathrm{m}$ in G,I; $5 \mu \mathrm{m}$ in O,Q-S,U; $2 \mu \mathrm{m}$ in P; $1 \mu \mathrm{m}$ in T. 
Fig. 8. In situ hybridization for Sema3c (A-C) and Sema5a (D-G) in wild-type (A,D,E), heterozygous (B) and $\operatorname{Pax6}^{-1-}(\mathrm{C}, \mathrm{F}, \mathrm{G})$ forebrains at E14.5. $(\mathrm{A}, \mathrm{B})$ In wild-type and heterozygous brains, Sema3c expression is seen within the subventricular (svz) and intermediate zone (iz) of the entire pallium, with a most prominent signal detected within svz/iz of the lateral and ventral pallium (arrows). The signal had sharp ending at the PSPB. (C) In the Pax6-lforebrain, the prominent expression of Sema3c in the svz/iz of the ventrolateral pallium is not detectable, while the expression in the dorsal pallium is shifted to the outermost surface of the developing cortical plate. (D-G) The normal strong expression of Sema5a in the ventricular zone (vz) of the entire pallium $(\mathrm{D}, \mathrm{E})$ is substantially diminished in the
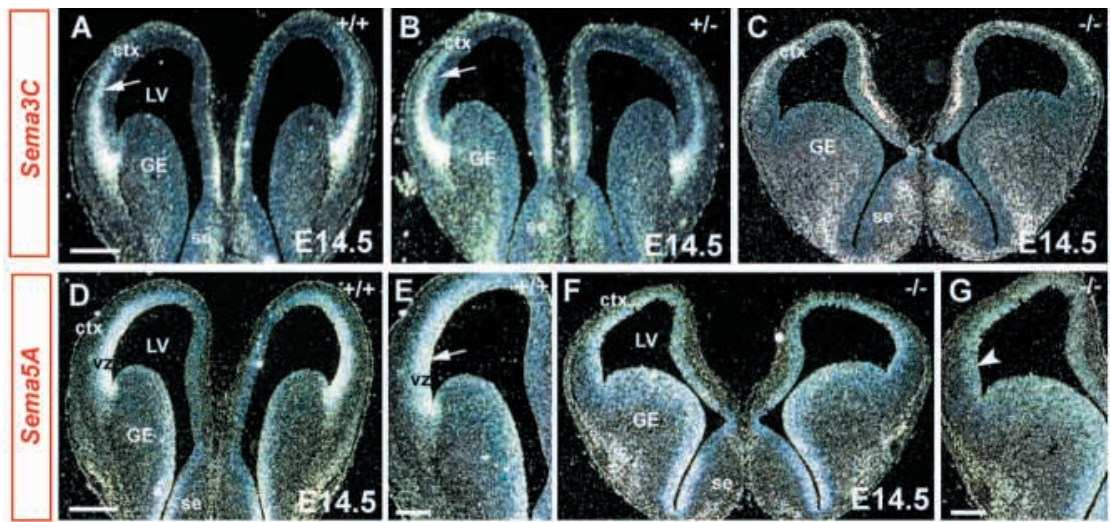

neuroepithelium of the $P a x 6^{-1-}$ brains (F,G). The arrowhead in G indicates to the strongly affected expression of Sema5a in the vz of the ventrolateral pallium of the $P a x 6^{--}$brains, when compared with the expression in wild-type (arrow in E). GE, ganglionic eminences; se, septal eminence. Scale bars: $200 \mu \mathrm{m}$ in A-C,G,I; $100 \mu \mathrm{m}$ in D-F,H,J.

observed at electron microscopy level traversing the PSPB in the $\operatorname{Pax}^{-1-}$ at both ages (Fig. 7H). At the lateral pallium of the Pax6 $^{-1-}$ brains, bundles of axons were observed extending superficially (Fig. 7J), possibly corresponding to the CFAs that in the mutant were seen to follow an aberrant trajectory along this area (see Fig. 4J,K).

\section{Altered expression of axonal guidance molecules in the Pax6 $^{-/-}$pallium}

In an attempt to look for possible molecular determinants for the observed aberrant growth of the CFAs and TCAs in the Pax6 $^{-1}$ brain, we examined the expression of several semaphorins (Sema3a, Sema3c, Sema5a, Sema5b and Sema6a) and netrin 1 , which have previously been implicated in thalamocortical and/or corticofugal pathfinding (Bagnard et
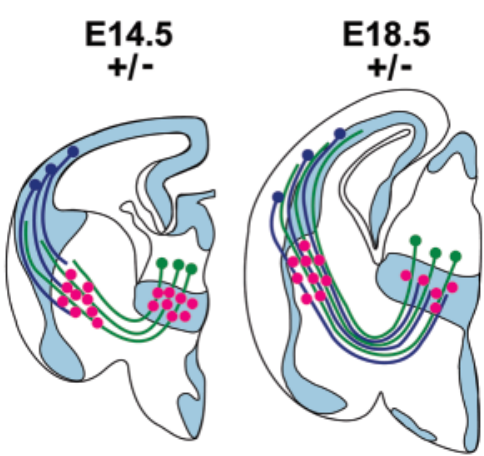

E14.5

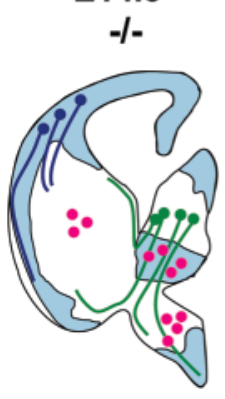

E18.5

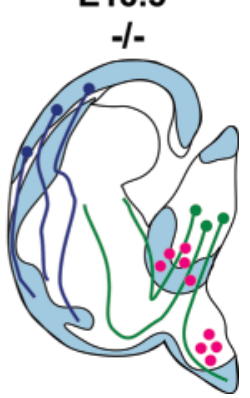

al., 1998; Métin et al., 1997). A prominent defect in the expression pattern of Sema3c and Sema $5 b$ was detected within the embryonic pallium in $\mathrm{Pax6}^{-1-}$ (Fig. 8). Sema3c is assumed to act as attractive axon guidance signal secreted by the cells of the SVZ (Bagnard et al., 1998). In agreement with Bagnard et al. (Bagnard et al., 1998), the expression of Sema3c in E14.5 wild-type cortex was confined to the SVZ and intermediate zone of the entire pallium, thus including the dorsal, lateral and ventral pallial domains (Fig. 8A). A similar pattern was seen in the heterozygous brains (Fig. 8B). However, in the Pax6 ${ }^{-1}$ brains the expression of Sema3c was completely abolished in the region of the ventral and lateral pallium, while in the dorsal pallium the expression was shifted into the most superficial zone of the cortical plate (Fig. 8C). In sections of E18.5 wildtype brains, the signal was fainter, but still detectable all along the extending CFAs towards the basolateral telencephalon (data not shown). Similarly as at stage E14.5, the expression of Sema3c was not detectable within the ventral and lateral pallium in the Pax $^{-1-}$ mice.

In wild-type brains, Sema5a had a strong expression in the $\mathrm{VZ}$ of the rostral pallium with a lateral (high) to medial (low) expression gradient (Fig. 8D,E). In the Pax6 ${ }^{-1-}$ brains, the lower expression level in the medial pallium was preserved, while the very prominent hybridization signal seen within the $\mathrm{VZ}$ at the PSPB was not visible any more (compare Fig. 8G with Fig. 8E, arrows). At E14.5, netrin 1 was expressed in the

Fig. 9. Schematic diagram illustrating the relationship between the developing reciprocal TCAs and CFA and $\beta$-galactosidase stained early subdivisions of the embryonic forebrain in $\operatorname{Pax6}^{+/-}$(upper row) and in $\operatorname{Pax6}^{-1-}$ (lower row) mice at E14.5 and E18.5. Blue represents the $\beta$-galactosidase staining, which reflects the Pax6 promoter activity. Red dots represent cells with dorsal thalamic projections. In wild-type and heterozygote mice at E14.5, early thalamic and corticofugal fibres synchronously approach the internal capsule. The growing CFAs (dark blue) pause at the border of the Pax6-positive compartment before they continue their journey towards the diencephalon and encounter the growing TCAs (green). By E18.5, both sets of axons have almost reached their destination and the Pax6 expression is gradually reduced in the PSPB and it is limited to the cortical intermediate zone, but continues to be present in the ventral pallium. In the $\operatorname{Pax6}^{-1-}$ mice, the cells with dorsal thalamic projection are displaced into the ventral IC and some to hypothalamus. TCAs descend into the hypothalamus and a subset of fibres cross the telencephalic-diencephalic junction at altered ventral or dorsal sites. The majority of the CFAs fail to turn into the internal capsule and continue to descend into the ventral pallium. The two sets of fibres fail to interact at the PSPB. 
basal telencephalon including the region of the primitive internal capsule (Métin et al., 1997). In the Pax6 $^{-1-}$ brains, the netrin 1 expression is present and might even appear stronger and more widespread than in wild-type (data not shown), extending to the region where the aberrant thalamic axons enter to the ventral telencephalon. These results suggest that the altered expression pattern of Sema3c, Sema5b and perhaps netrin 1 in the Pax6 mutant may be responsible for the altered growth of the CFAs and TCAs.

\section{DISCUSSION}

In this study, we show that Pax6 is involved in pathfinding not only of the thalamocortical, but also of the corticofugal axonal connections (Fig. 9). The abnormalities are complex and numerous factors might be responsible for the failure of both CFAs and TCAs to navigate to their targets. We demonstrate that in $\mathrm{Pax6}^{-1-}$ brains, cells with early dorsal thalamic projection at the internal capsule are more dispersed. In addition, alterations in the structure of the PSPB were observed, together with the failure of expression of axon attractive molecules Sema3c, Sema5a and netrin 1. The results suggest that the prominent ventralization of the molecular patterning at the PSPB as shown previously (Stoykova et al., 2000; Toresson et al., 2000; Yun et al., 2001), might affect environmental cues and differentiation of guide-post cells within the internal capsule and at the PSPB regions, both of which are essential for the TCAs to reach the cortex.

\section{Aberrant TCA fibre growth is associated with disturbed CFA projections in the Pax6 ${ }^{-/}$mice}

We have previously suggested in our 'handshake hypothesis', that axons from the thalamus and from the early-born cortical preplate cells meet and intermingle in the basal telencephalon, so that thalamic axons grow over the scaffold of preplate axons and become 'captured' for the waiting period in the subplate (Blakemore and Molnár, 1990; Molnár and Blakemore, 1995). The use of the Pax6 $^{-1-}$ mice (St-Onge et al., 1997) allowed us to examine the relationship between Pax6 expression at the PSBP and the cortical connectivity in normal and in Pax6 lossof-function conditions. In agreement with previous results (Kawano et al., 1999; Pratt et al., 2000; Hevner et al., 2002), we found that the lack of PAX6 resulted in a failure of TCA growth into the telencephalon, which is accompanied by a misrouting of the majority of the TCAs into the hypothalamus. Remarkably, DiI labelling of the mutant cortex revealed that, in addition to TCAs, the CFAs also follow an aberrant trajectory with an abnormal fasciculation pattern. Although perinatally (E18.5) the thalamic axons reach the PSPB, they are not able to cross this region. Double DiI/DiA labelling experiments clearly indicated that no interactions occur between TCAs and CFAs within the internal capsule, and these two sets of axons remained separated by the PSPB. These observations were further supported by the L1 and TAG1 immunohistochemistry results. The aberrant development of these tracts may be partly explained by abnormal axonal fasciculation because CFAs and TCAs would be unable to interact and use each other as a scaffold to extend towards their targets. Accordingly, mice with mutations in transcription factor genes expressed in the pallium (Tbrl) and dorsal thalamus (Gbx2), show TCA and CFA pathfinding errors in the region of the internal capsule (Miyashita-Lin et al., 1999; Hevner et al., 2001; Hevner et al., 2002). Tracing experiments in these knockout mice have shown that lack of early CFA is associated with abnormal development of TCAs. It is conceivable therefore that the development of both fibre systems depends on the same factors requiring the intact morphology of the PSPB and/or interactions between the two fibre systems.

\section{How does Pax6 affect TCA and CFA pathfinding?}

The lack of $P a x 6$ in the $P a x 6^{S e y / S e y}$ causes a complex phenotype reflected in defects of the molecular regionalization and boundary formation in developing telencephalon (Stoykova et al., 1996; Stoykova et al., 1997; Stoykova et al., 2000; Warren and Price, 1997; Toresson et al., 2000; Yun et al., 2001), axonal pathfinding (Mastick et al., 1997; Pratt et al., 2000), adhesive properties (Stoykova et al., 1997; Meech et al., 1999), cortical progenitor proliferation (Warren et al., 1999), cell migration (Caric et al., 1997; Brunjes et al., 1998; Chapouton et al., 1999), radial glia differentiation (Götz et al., 1998) and neurogenesis (Heins et al., 2002). This phenotype is established early in embryonic development, and becomes progressively more complex at later stages, which seriously hampers the determination of the primary effect of Pax6 in the developing brain.

The choreography and timing of developmental events seem to be important for the normal development of telencephalic connectivity. We identified several defects of TCA development in the $\operatorname{Pax}^{-/-}$brains. It is conceivable that changes in the location of forebrain domains, and their boundaries, may displace transient 'guide-post' cells and their pioneering projections, which are thought to be crucial for TCA guidance (Métin and Godement, 1996; Molnár et al., 1998). Cells with similar function have been described within the internal capsule and ventral thalamus in numerous species (Molnár, 1998). In lack of Pax6 in the Pax6 $6^{\text {Sey/Sey, the }}$ differentiation of the ventral thalamic nuclei is completely abolished (Stoykova et al., 1996; Warren and Price, 1997) (Fig. $1 \mathrm{H})$, including the reticular nucleus, which has an essential role in the control of the thalamocortical circuits (Mitrofanis and Guillery, 1993). We found that only a few thalamic projecting cells were labelled within the PSBP after a thalamic placement of the DiI crystals and these cells were displaced towards the hypothalamus. In the developing telencephalon, Pax6 expression is confined to the germinal neuroepithelium (VZ/SVZ) with a rostrolateral (high) to caudomedial (low) gradient, with a most prominent expression within the lateral and ventral pallium (Stoykova et al., 1997; Smith-Fernandez et al., 1998; Puelles et al., 2000). In the $\operatorname{Pax6}^{-{ }^{-}}$at the pallial VZ, there is an intensive ectopic expression of ventral markers in the lateral and dorsal pallium, which seems to include direct transcriptional regulation between other genes, e.g. Pax6 and Ngn2; Pax6 and Gbx2 (Stoykova et al., 2000; Toresson et al., 2000; Yun et al., 2001). These pattern abnormalities seem to affect the progenitor identity of the ventrolateral telencephalon, leading to a failure of the lateral cortical plate formation and a dysgenesis of basolateral structures, claustrum, endopiriform nucleus and piriform cortex (Stoykova et al., 2000). It is conceivable therefore that the described defects in the generation and/or functional properties of the TCAs, guidepost cells within the internal capsule, ventral thalamus and 
perhaps hypothalamus might be a further consequence of the ventralization of the telencephalic neuroepithelium at the PSBP border in Pax6 $^{-1-}$ mice.

Semaphorins are thought to be involved in cortical and thalamic axon guidance (Puschel, 1999; Skaliora et al., 1998). In the Pax $6^{-/}$brains, the expression of Sema3c was completely abolished from the SVZ and IZ of the lateral and ventral pallium, thus including the region where the CFA defects were observed. In the dorsal pallium, however, the expression was shifted into the most superficial zone of the cortical plate. Sema3c (previously known as SemE) is assumed to act as attractive axon guidance signal secreted mostly by the cells of the SVZ (Bagnard et al., 1998). Thus, the abnormal expression pattern of Sema3c in the Pax $6^{-1-}$ brain correlates well with both, the CFA pathfinding defects within the PSBP and with the aberrant orientation of the cortical axons towards the cortical surface and might be responsible for them.

It has been suggested that secreted chemoattractants, e.g. netrin 1, might influence the growth of navigating axons, especially when they change their direction of growth (Métin et al., 1997; Braisted et al., 2000; Tessier-Lavigne and Goodman, 1996). As reported in this work, the expression of netrin 1 in the basal telencephalon of the $\operatorname{Pax}^{-1-}$ embryos (including the region of the internal capsule) was present and appeared wider and stronger, when compared with the wildtype brain, which might additionally hamper the proper growth of the early TCA axons through the altered environment in the mutant. This possible difference in netrin 1 expression pattern shall need further quantitative analysis.

Previous evidence indicated that the expanded VZ/SVZ in the $P a x 6^{S e y / S e y}$ pallium is a consequence of accumulation of only partially differentiated (Stoykova et al., 2000; Heinz et al., 2002) or prematurely differentiated (Warren et al., 1999) neuroblasts. Furthermore, in this mutant, the adhesiveness of pallial cells is increased, accompanied by a severe downregulation of the expression of the homophilic celladhesion molecule R-cadherin and of tenascin (Stoykova et al., 1977; Warren et al., 1999). We have described similar abnormalities at the PSPB in the $\operatorname{Pax}^{-1-}$. The densely packed adhering cells especially apparent at the anterior part of this boundary might not be penetrable for TCAs or CFA, thus making an additional obstacle for the TCAs and CFA to traverse the IC, the gateway between thalamus and cortex.

\section{Are axonal pathfinding and cortical regionalization defects related?}

There is a continuing debate as to how the developing pallium influences TCA development, and in turn whether TCAs affect development of the cortex. It has been demonstrated that there is a shift in the areal identity in the cerebral cortex of Emx2 and $P a x 6^{S e y / S e y}$ mutant mice, which is matched with altered distribution of TCAs in the Emx $2^{-1-}$ brains (Bishop et al., 2000; Mallamaci et al., 2000). In the Pax $6^{-1-}$ brains, no thalamic projections reach the cortex, suggesting that the shift observed in cortical representation in the $\operatorname{Pax}^{-{ }^{-}-}$cortex might be in fact independent from TCA targeting and do not rely on the presence or absence of thalamic projections. Our tracing studies demonstrated that in both $E m x 2^{-/-}$(López-Bendito et al., 2002) and $\operatorname{Pax}^{-/-}$mice (present study) a large proportion or the entire early TCA population were misrouted at the border between the diencephalon and telencephalon. In addition, in the $\mathrm{Pax}^{-1-}$ an additional defect prevented the TCAs from invading the cortex through the PSPB. Although, both of these early TCA targeting abnormalities are associated with the altered cortical Emx2 and Pax6 expression patterns they are related to earlier guidance defects, most probably independent from the cortical alterations.

In summary, we have found that axonal pathfinding and fasciculation of both CFA and TCA are dependent upon the normal expression of Pax 6 during early forebrain development. The pathfinding defects may be secondary to displacement and dispersion of guidepost cell populations within the ventral thalamus and internal capsule and to abnormal barrier formation at the PSPB as a result of defects in molecular patterning. These cellular changes are also associated with altered expression of proteins (including Sema3c, Sema5a and netrin 1) required for normal axonal guidance. Our study suggests that Pax6 has numerous roles in thalamocortical guidance, and these seem to be independent from the cortical regionalization.

The excellent technical support of Ms Silke Eckert and Mr David Modoux is gratefully acknowledged. We are very grateful to Professor John Parnavelas and Dr Richard Branton for their thoughtful comments on the manuscript. We are grateful to Andreas Puschel and Marc Tessier-Lavigne for their help with the probes. L. J. held a BBSRC studentship. This work was supported by Grants from The European Community (QLRT-1999-30158, QLG3-CT-2000-00158), The Wellcome Trust (063974/B/01/Z), The Royal Society, Swiss National Science Foundation (3100-56032.98), Human Frontier Science Program (RGP0107/2001) and St John's College, Oxford.

\section{REFERENCES}

Bagnard, D., Lohrum, M., Uziel, D., Puschel, A. W. and Bolz, J. (1998). Semaphorins act as attractive and repulsive guidance signals during the development of cortical projections. Development 125, 5043-5053.

Bishop, K. M., Goudreau, G. and O'Leary, D. D. (2000). Regulation of area identity in mammalian neocortex by Emx2 and Pax6. Science 288, 344-349.

Blakemore, C. and Molnár, Z. (1990) Factors involved in the establishment of specific interconnections between thalamus and cerebral cortex. Cold Spring Harb. Symp. Quant. Biol. 55, 491-504.

Braisted, J. E., Catalano, S. M., Stimac, R., Kennedy, T. E., TessierLavigne, M., Shatz, C. J. and O'Leary, D. D. (2000). Netrin-1 promotes thalamic axon growth and is required for proper development of the thalamocortical projection. J. Neurosci. 20, 5792-5801.

Brunjes, P. C., Fisher, M. and Grainger, R. (1998). The small-eye mutation results in abnormalities in the lateral cortical migratory stream. Dev. Brain Res. 110, 121-125.

Caric, D., Gooday, D., Hill, R. E., McConnell, S. K. and Price, D. J. (1997). Determination of the migratory capacity of embryonic cortical cells lacking the transcription factor Pax-6. Development 124, 5087-5096.

Catalano, S., Robertson, R. T. and Killackey, H. P. (1991). Early ingrowth of thalamocortical afferents to the neocortex of the prenatal rat. Proc. Natl. Acad. Sci. USA 88, 2999-3003.

Chapouton, P., Gartner, A. and Gotz, M. (1999). The role of Pax6 in restricting cell migration between developing cortex and basal ganglia. Development 126, 5569-5579.

De Carlos, J. A. and O'Leary, D. D. (1992). Growth and targeting of subplate axons and establishment of major cortical pathways. J. Neurosci. 12, 11941211.

Denaxa, M., Chan, C. H., Schachner, M., Parnavelas, J. G. and Karagogeos, D. (2001). The adhesion molecule TAG-1 mediates the migration of cortical interneurons from the ganglionic eminence along the corticofugal fiber system. Development 128, 4635-4644.

Erzurumlu, R. S. and Jhaveri, S. (1992). Emergence of connectivity in the embryonic rat parietal cortex. Cereb. Cortex 2, 336-352.

Fernandez, A. S., Pieau, C., Reperant, J., Boncinelli, E. and Wassef, M. 
(1998). Expression of the Emx-1 and Dlx-1 homeobox genes define three molecularly distinct domains in the telencephalon of mouse, chick, turtle and frog embryos: implications for the evolution of telencephalic subdivisions in amniotes. Development 125, 2099-2111.

Fukuda, T., Kawano, H., Ohyama, K., Li, H. P., Takeda, Y., Oohira, A. and Kawamura, K. (1997). Immunohistochemical localization of neurocan and L1 in the formation of thalamocortical pathway of developing rats. $J$. Comp. Neurol. 382, 141-152.

Gossler, A. and Zachgo, J. (1993) Gene and enhancer trap screen in ES cell chimeras. In Gene Targeting: A Practical Approach (ed. A. L. Joyner), pp. 181-225. Oxford: Oxford University Press.

Götz, M., Stoykova, A. and Gruss, P. (1998). Pax6 controls radial glia differentiation in the cerebral cortex. Neuron 21, 1031-1044.

Heins, N., Malatesta, P., Cecconi, F., Nakafuku, M., Tucker, K. L., Hack, M. A., Chapouton, P., Barde, Y. A. and Gotz, M. (2002) Glial cells generate neurons: the role of the transcription factor Pax6. Nat. Neurosci. 5, 308-315.

Hevner, R. F., Shi, L., Justice, N., Hsueh, Y., Sheng, M., Smiga, S., Bulfone, A., Goffinet, A. M., Campagnoni, A. T. and Rubenstein, J. L. (2001). Tbr1 regulates differentiation of the preplate and layer 6. Neuron 29, 353366

Hevner, R. F., Miyashita-Lin, E., Rubenstein, J. L. R. (2002) Cortical and thalamic axon pathfinding defects in Tbr1, Gbx2 and Pax6 mutant mice: Evidence that cortical and thalamis axons interact and guide each other. $J$. Comp Neurol. 447, 8-17.

Hill, R. E., Favor, J., Hogan, B. L., Ton, C. C., Saunders, G. F., Hanson, I. M., Prosser, J., Jordan, T., Hastie, N. D. and van Heyningen, V. (1991). Mouse small eye results from mutations in a paired-like homeoboxcontaining gene. Nature 354, 522-525.

Kawano, H., Fukuda, T., Kubo, K., Horie, M., Uyemura, K., Takeuchi, K., Osumi, N., Eto, K. and Kawamura, K. (1999). Pax-6 is required for thalamocortical pathway formation in fetal rats. J. Comp. Neurol. 408, 147160.

López-Bendito, G., Chan, C.-H., Mallamaci, A., Parnavelas, J. and Molnár, Z. (2002) The role of Emx2 in the development of the reciprocal connectivity between cortex and thalamus. J. Comp. Neurol. 451, 153-169.

Mallamaci, A., Muzio, L., Chan, C. H., Parnavelas, J. and Boncinelli, E. (2000). Area identity shifts in the early cerebral cortex of $E m \times 2^{--}$mutant mice. Nat. Neurosci. 3, 679-686.

Mastick, G. S., Davis, N. M., Andrew, G. L. and Easter, S. S., Jr (1997). Pax-6 functions in boundary formation and axon guidance in the embryonic mouse forebrain. Development 124, 1985-1997.

McConnell, S. K., Ghosh, A. and Shatz, C. J. (1989). Subplate neurons pioneer the first axon pathway from the cerebral cortex. Science $\mathbf{2 4 5}$, 978982.

Meech, R., Kallunki, P., Edelman, G. M. and Jones, F. S. (1999). A binding site for homeodomain and Pax proteins is necessary for L1 cell adhesion molecule gene expression by Pax-6 and bone morphogenetic proteins. Proc. Natl. Acad. Sci. USA 96, 2420-2425.

Menezes, J. R. and Luskin, M. B. (1994) Expression of neuron-specific tubulin defines a novel population in the proliferative layers of the developing telencephalon. J. Neurosci. 14, 5399-5416.

Métin, C. and Godement, P. (1996). The ganglionic eminence may be an intermediate target for corticofugal and thalamocortical axons. J. Neurosci. 16, 3219-3235.

Métin, C., Deleglise, D., Serafini, T., Kennedy, T. E. and Tessier-Lavigne, M. (1997) A role for netrin-1 in the guidance of cortical efferents. Development 124, 5063-5074.

Mitrofanis, J. and Guillery, R. W. (1993). New views of the thalamic reticular nucleus in the adult and the developing brain. Trends Neurosci. 16, 240-245.

Miyashita-Lin, E. M., Hevner, R., Wassarman, K. M., Martinez, S. and Rubenstein, J. L. (1999). Early neocortical regionalization in the absence of thalamic innervation. Science 285, 906-909.

Molnár, Z. and Blakemore, C. (1995). How do thalamic axons find their way to the cortex? Trends Neurosci. 18, 389-397.

Molnár, Z. (1998) Development of Thalamocortical Connections. Heidelberg: Springer.

Molnár, Z., Adams, R. and Blakemore, C. (1998). Mechanisms underlying the early establishment of thalamocortical connections in the rat. $J$. Neurosci. 18, 5723-5745.

Pratt, T., Vitalis, T., Warren, N., Edgar, J. M., Mason, J. O. and Price, D. J. (2000). A role for Pax6 in the normal development of dorsal thalamus and its cortical connections. Development 127, 5167-5178.

Puelles, L., Kuwana, E., Puelles, E., Bulfone, A., Shimamura, K., Keleher, J., Smiga, S. and Rubenstein, J. L. (2000). Pallial and subpallial derivatives in the embryonic chick and mouse telencephalon, traced by the expression of the genes Dlx-2, Emx-1, Nkx- 2.1, Pax-6, and Tbr-1. J. Comp. Neurol. 424, 409-438.

Puelles, L. and Rubenstein, J. L. (1993). Expression patterns of homeobox and other putative regulatory genes in the embryonic mouse forebrain suggest a neuromeric organization. Trends Neurosci. 16, 472-479.

Puschel, A. W. (1999) Semaphorins: repulsive guidance molecules show their attractive side. Nat. Neurosci. 2, 777-778.

Scardigli, R., Schuurmans, C., Gradwohl, G. and Guillemot, F. (2001) Crossregulation between Neurogenin2 andpathways specifying neuronal identity in the spinal cord. Neuron 31, 203-217.

Schmahl, W., Knoedlseder, M., Favor, J. and Davidson, D. (1993). Defects of neuronal migration and the pathogenesis of cortical malformations are associated with Small eye (Sey) in the mouse, a point mutation at the Pax6-locus. Acta Neuropathol. 86, 126-135.

Skaliora, I., Betz, H. and Puschel, A. W. (1998) Differential patterns of semaphorin expression in the developing rat brain. Eur. J. Neurosci. 10, 1215-1229.

Smith-Fernandez, A., Pieau, C., Reperant, J., Boncinelli, E. and Wassef, M. (1998). Expression of the Emx-1 and Dlx-1 homeobox genes define three molecularly distinct domains in the telencephalon of mouse, chick, turtle and frog embryos: implications for the evolution of telencephalic subdivisions in amniotes. Development 125, 2099-2111.

St-Onge, L., Sosa-Pineda, B., Chowdhury, K., Mansouri, A. and Gruss, P. (1997). Pax6 is required for differentiation of glucagon-producing alphacells in mouse pancreas. Nature 387, 406-409.

Stoykova, A. and Gruss, P. (1994). Roles of Pax-genes in developing and adult brain as suggested by expression patterns. J. Neurosci. 14, 1395-1412.

Stoykova, A., Fritsch, R., Walther, C. and Gruss, P. (1996). Forebrain patterning defects in Small eye mutant mice. Development 122, 3453-3465.

Stoykova, A., Gotz, M., Gruss, P. and Price, J. (1997). Pax6-dependent regulation of adhesive patterning, R-cadherin expression and boundary formation in developing forebrain. Development 124, 3765-3777.

Stoykova, A., Chowdhury, K., Bonaldo, P., Torres, M. and Gruss, P. (1998) Gene trap expression and mutational analysis for genes involved in the development of the mammalian nervous system. Dev. Dyn. 212, 198213.

Stoykova, A., Treichel, D., Hallonet, M. and Gruss, P. (2000). Pax6 modulates the dorsoventral patterning of the mammalian telencephalon. $J$. Neurosci. 20, 8042-8050.

Tessier-Lavigne, M. and Goodman, C. S. (1996). The molecular biology of axon guidance. Science 274, 1123-1133.

Toresson, H., Potter, S. S. and Campbell, K. (2000) Genetic control of dorsal-ventral identity in the telencephalon: opposing roles for Pax6 and Gsh2. Development 127, 4361-4371.

Tuttle, R., Nakagawa, Y., Johnson, J. E. and O'Leary, D. D. (1999). Defects in thalamocortical axon pathfinding correlate with altered cell domains in Mash-1-deficient mice. Development 126, 1903-1916.

Walter, C. and Gruss, P. (1991). Pax-6, a murine paired box gene, is expressed in the developing CNS. Development 113, 1435-1449.

Warren, N. and Price, D. J. (1997). Roles of Pox-6 in murine diencephalic development. Development 124, 1573-1582.

Warren, N., Caric, D., Pratt, T., Clausen, J. A., Asavaritikrai, P., Mason, J. O., Hill, R. E. and Price, D. J. (1999). The transcription factor, Pax6, is required for cell proliferation and differentiation in the developing cerebral cortex. Cereb. Cortex 9, 627-635.

Wilson, S. W. Brennan, C. Macdonald, R. Brand, M. Holder, N. (1997). Analysis of axon tract formation in the zebrafish brain: the role of territories of gene expression and their boundaries. Cell Tissue Res. 290, 189-196.

Yun, K., Potter, S. and Rubenstein, J. L. (2001). Gsh2 and Pax6 play complementary roles in dorsoventral patterning of the mammalian telencephalon. Development 128, 193-205. 